\title{
Sequence Stratigraphy, Reservoirs, Diagenesis and Hydrocarbon Contents in the Khuff Formation and its Equivalents: Independent or Linked?
}

\author{
Roger B. Davies \\ (Neftex Petroleum Consultants Ltd, roger.davies@neftex.com)
}

Thirty years ago, the author undertook a detailed sedimentological, petrographic and reservoir quality evaluation of extensive cores through the Khuff Formation from Well Zakum-182 in offshore Abu Dhabi. Many new observations, including detailed depositional and early diagenetic fabrics preserved during dolomite replacement and the presence of sulphur as a late diagenetic phase infilling the cores of anhydrite nodules, vugs and fractures, ignited a lifelong interest in this fascinating formation and its equivalents, notably the Dalan and Kangan formations of Iran. This was followed by a much larger project in which the author, as part of a multi-disciplinary team, was responsible for a regional analysis of the sedimentology, diagenesis and reservoir quality of the Khuff Formation over a wide area ranging from subsurface sections in Abu Dhabi, Dubai and Qatar to outcrops in Saudi Arabia, Oman and the Musandam Peninsula. Studies since then have ranged from a sequence-stratigraphic analysis over the entire Arabian Plate to analyses of depositional sedimentology, diagenesis, reservoir architecture, reservoir quality and relationships between geology and gas contents. As a result of working this range of studies, the author proposes that, even though masked by complex depositional and post-depositional factors, there are significant relationships between the sequence-stratigraphic organisation of the Khuff Formation and its mineralogy, diagenesis, reservoir architecture, reservoir properties, compartmentalisation and even gas composition, all of which impact the value of its enormous gas resources. This presentation reviews each of these relationships and how our understanding of the Khuff Formation has evolved over the last 30 years. 